\title{
Stroke, Carotid Thrombosis and Other Thrombotic Events in Essential Thrombocythemia Patient with a High Quantity of Micromegakaryocytes
}

\author{
Miguel Augusto Pereira*1, Suelen Brito ${ }^{2}$ and Hye Chung-Kang ${ }^{3}$ \\ ${ }^{1}$ Department of Pathology and Clinical Hematology, Undergraduate Medical School, Fluminense Federal University, Niterói, Rio de Janeiro, \\ Brazil \\ ${ }^{2}$ Department of General Pathology, Fluminense Federal University, Niterói, Rio de Janeiro, Brazil \\ ${ }^{3}$ Department of Pathology, Fluminense Federal University, Niterói, Rio de Janeiro, Brazil
}

${ }^{*}$ Corresponding author: Miguel Augusto Pereira, Medical Undergraduate, Department of Pathology and Clinical Hematology, Medical School, Fluminense Federal University, 303 Ave. Marquês do Paraná, Niterói, RJ, 24033-900, Brazil, Tel: +552126299095; E-mail: mappereira@icloud.com.br

Received date: August 05, 2019; Accepted date: September 20, 2019; Published date: September 27, 2019

Citation: Pereira MA, Brito S, Chung-Kang H (2019) Stroke, Carotid Thrombosis and Other Thrombotic Events in Essential Thrombocythemia Patient with a High Quantity of Micromegakaryocytes. Arch Med Vol: 11 Iss: 3:1

Copyright: (C2019 Pereira MA, et al. This is an open-access article distributed under the terms of the Creative Commons Attribution License, which permits unrestricted use, distribution, and reproduction in any medium, provided the original author and source are credited.

\section{Abstract}

Essential thrombocythemia is a myeloproliferative neoplasm characterized by thrombocytosis and possible complications such as thrombosis, hemorrhage, splenomegaly, bone marrow failure and acute leukemia. In the myeloproliferatives neoplasms, there is an increase number of dysplastic megakaryocytes, known as micromegakaryocytes and there is an association between the high expression of the JAK2 $2^{\mathrm{V} 617 \mathrm{~F}}$ mutation and the presence of micromegakaryocytes in bone marrow. To date, reports and researches involving essential thrombocythemia and micromegakaryocytes are exceedingly scarce. We report a peculiar and unique case of a death of a 55-year-old man, due to stroke and carotid thrombosis, preceded by successive thrombotic events in a patient with essential thrombocythemia, JAK2 positive, with no additional risk factor, who did not respond well to standard treatment and had a high amount of circulating micromegakaryocytes in peripheral blood. This case goes beyond the known prognosis of ET and raises the discussion of new prognostic markers, such as the quantification of micromegakaryocytes and reaffirms the importance of the JAK2 mutation in the evolution of the disease. We also discuss the involvement of micromegakaryocytes in the probable mechanisms leading to our patient's thrombotic state.

Keywords: JAK2 mutation; Thrombocytosis; Hematology; Thrombosis; Peripheral blood

\section{Introduction}

Essential Thrombocythemia (ET) is a Myeloproliferative Neoplasm (MPN) characterized by thrombocytosis and, like others MPNs, has complications such as thrombosis, hemorrhage, splenomegaly, bone marrow failure and a possible course to acute leukemia [1]. In addition, there are reports of patients with ET that have developed from thrombosis of celiac and superior mesenteric arteries [2], thrombosis of cerebral venous sinuses [3] to pericarditis [4].

In MPNs, abnormal transient myelopoiesis and, more characteristically, myelodysplastic syndrome, there is an increase in the number of dysplastic megakaryocytes, known as micromegakaryocytes (mMK). The International Working Group on Morphology of MDS (IWGM-MDS) defined them as generally diploid, mononuclear cells with a nucleus similar in size to that of a myeloblast or promyelocyte and less than 30 $\mu \mathrm{m}$ in diameter [5].

In a study conducted by Pich, it was found that the high expression of the JAK2 ${ }^{\mathrm{V} 617 \mathrm{~F}}$ mutation in patients with $\mathrm{ET}$ is associated with a higher presence of $\mathrm{mMK}$ in bone marrow biopsies [6]. However, little is known about the relationship between the presence of $\mathrm{mMK}$ in peripheral blood and the occurrence of such thrombotic events.

Here we present the case of a patient diagnosed with ET, who died after successive thrombotic events, both arterial and venous, with no additional predisposing factor, in a short period of time. The large amount of $\mathrm{mMK}$ and the presence of the JAK2 mutation are the main peculiarities of the case.

\section{Case Presentation}

A 55-year-old white male was admitted in November 2012 to investigate a thrombocytosis detected on a routine exam. The patient had no symptoms or any other complaint. The possible cause of thrombocytosis was identified in 2013 when the diagnosis of ET was given. The patient's diagnosis complies with the WHO criteria, which are based on clinical and laboratory characteristics [7]. Their initial platelet count was 
greater than $450 \times 10^{9} / \mathrm{L}$, a bone marrow biopsy (BMB) confirmed the ET. The presence of the JAK2 ${ }^{\mathrm{V} 617 \mathrm{~F}}$ mutation was also evaluated (positive).

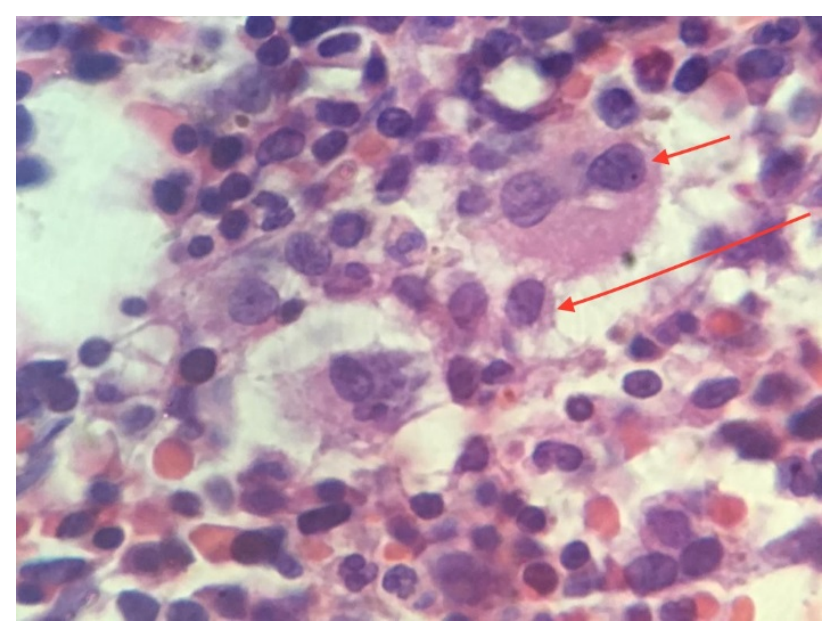

Figure 1 Bone marrow biopsy of the patient (HE staining, original magnification 40x). The major arrow points to a micromegacarocyte, while the smaller one, a binucleate megakaryocyte.

Therefor cytoreductive therapy with anagrelide $(0.5 \mathrm{mg} / 2 \times$ day), hydroxyurea (1.5 $\mathrm{mg} /$ day) and anti-aggregative with acetylsalicylic acid (100 mg/day) was started, which maintained his platelet count controlled. The patient did not report a history of alcohol or tobacco use and did not present any other comorbidities. However, within a few months, despite the standard therapy, the patient presented ulcers and thrombosis of both lower limbs, as well as ischemia of the fifth toe.

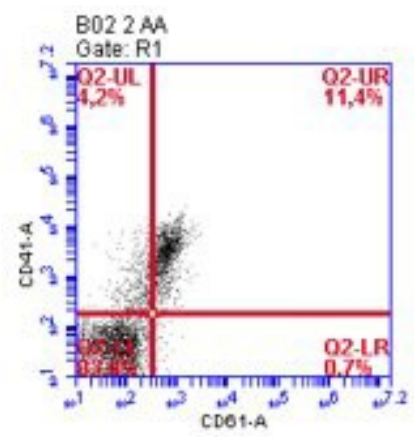

Figure 2 Peripheral blood analysis of the patient by flow cytometry. The percentage of cells expressing double labeling for the CD41 and CD61 markers, which are indicative of micromegacarocytes (mMK) is observed in the Dot plot.
In July 2016, another BMB confirmed the myeloproliferative disease, type ET, with mild fibrosis (grade 1). It was also excluded other myeloid malignancies and other causes of reactive thrombocytosis. Small, monolobular megakaryocytes with high nucleus/cytoplasm ratio were found on the slides, compatible with micromegacarocytes (Figure 1).

In February 2017, the patient was recruited for a quantification study of $\mathrm{mMK}$ in peripheral blood using flow cytometry (Figure 2) and almost 7 times the amount of these cells was observed compared to a healthy person [8]. At the same time, their blood counts revealed LDH and platelet counts within the reference values, but red blood cell counts, lymphocytes, and leukocytes were reduced, as well as hemoglobin levels (Table 1). The patient died in June 2017 after an ischemic stroke associated with carotid thrombosis.

\section{Discussion}

Hitherto it is unusual for a case to report so many thrombotic events in the same patient with ET and /or to relate them to the high amount of $\mathrm{mMK}$ in peripheral blood. However, the medical literature is rich in the collection of thrombo-hemorrhagic events. In a systematic review of Panayiotis D. Ziakas, thrombotic events were observed in $31.8 \%$ of cases positive for the JAK2 mutation [9]. While in the analysis conducted by Lussana, such thrombotic events, whether arterial or venous, occurred in $32 \%$ of patients with the JAK2 mutation [1]. In addition, the literature presents a greater number of cases of thrombosis in patients with ET and mutation carriers, splanchnic veins (including the hepatic portal vein) and deep venous system, with an incidence of $11 \%$ and $23 \%$, respectively [10].

It is also worth mentioning that the current risk stratification for patients with ET is based on predictors of arterial thrombosis, such as age less than 60 years, history of thrombosis, cardiovascular risk factors (CV). In addition to the use of tobacco, hypertension or diabetes mellitus, leukocytosis $\left(>11 \times 10^{9} / \mathrm{L}\right)$ and the presence of the JAK2 ${ }^{\mathrm{V} 617 \mathrm{~F}}$ mutation [11].

The patient not only had deep vein involvement but also developed the curious event of carotid thrombosis associated with a stroke. Although there is no CV risk factor, no tobacco or alcohol use, no history of previous surgeries, splenomegaly, hypertension, overweight or diabetes mellitus, and did not have a leukometry lower than $15,000 / \mathrm{mm}^{3}$, indicated as an isolated risk factor for thrombosis [12]. A recent study revealed the association between monocytosis and deep venous thrombosis, but the patient did not present monocytosis at any time (Table 1) [13-17].

The patient survived a little more than 3 years after his diagnosis, not corresponding to the average survival of 33 years for patients with ET less than 60 years of age [13]. In addition, several thrombotic events occurred in this interval, even with the standard treatment for patients with high-risk 
ET, which consists of systemic anticoagulation conjugated to a cytoreductive therapy, as already mentioned.

Table 1 Table with results of laboratory tests of the patient. *Note: Total white blood cell count (WBC), Red blood cells count (RBC), Lactate dehydrogenase (LDH).

\begin{tabular}{|c|c|c|c|c|c|c|c|c|}
\hline Date & $\begin{array}{l}\text { LDH } \\
\text { (U/L) }\end{array}$ & $\begin{array}{l}\text { Glucose } \\
\text { (mg/dL) }\end{array}$ & $\begin{array}{l}\text { WBC } \\
\left(10^{3} / \mathrm{mm}^{3}\right)\end{array}$ & $\begin{array}{l}\text { Platelets } \\
\left(10^{3} / \mathrm{mm}^{3}\right)\end{array}$ & $\operatorname{RBC}\left(10^{6} / \mathrm{mm}^{3}\right)$ & $\begin{array}{l}\text { Haemoglobin } \\
(\mathrm{g} / \mathrm{dL})\end{array}$ & $\begin{array}{l}\text { Lymphocytes } \\
\left(10^{3} / \mathrm{mm}^{3}\right)\end{array}$ & $\begin{array}{l}\text { Monocytes } \\
\left(10 / \mathrm{mm}^{3}\right)\end{array}$ \\
\hline $\begin{array}{l}28-04-20 \\
17\end{array}$ & 216 & 88 & 8.80 & 730 & 2.93 & 11.00 & 1.76 & 0.44 \\
\hline $\begin{array}{l}17-02-20 \\
17\end{array}$ & & & 3.10 & 241 & 2.06 & 8.90 & 0.78 & 0.21 \\
\hline $\begin{array}{l}15-12-20 \\
16\end{array}$ & & & 3.60 & 254 & 2.23 & 9.90 & 0.86 & 0.18 \\
\hline $\begin{array}{l}20-10-20 \\
16\end{array}$ & & & 4.90 & 419 & 2.36 & 9.40 & 0.78 & 0.25 \\
\hline $\begin{array}{l}15-08-20 \\
16\end{array}$ & & & 8.80 & 638 & 2.52 & 9.70 & 0.74 & 0.50 \\
\hline $\begin{array}{l}09-06-20 \\
16\end{array}$ & 306 & 90 & 10.20 & 866 & 2.49 & 8.70 & 1.22 & 0.51 \\
\hline $\begin{array}{l}10-05-20 \\
16\end{array}$ & & & 5.20 & 555 & 2.04 & 6.80 & 1.04 & 0.26 \\
\hline $\begin{array}{l}19-04-20 \\
16\end{array}$ & & & 6.20 & 624 & 2.53 & 7.80 & 0.99 & 0.31 \\
\hline $\begin{array}{l}29-03-20 \\
16\end{array}$ & & & 9.10 & 1051 & 2.34 & 7.40 & 1.46 & 0.47 \\
\hline $\begin{array}{l}15-12-20 \\
15\end{array}$ & & & 9.90 & 874 & 2.37 & 8.00 & 1.19 & 0.49 \\
\hline $\begin{array}{l}03-08-20 \\
15\end{array}$ & & & 11.10 & 671 & 2.79 & 8.40 & 1.33 & 0.50 \\
\hline $\begin{array}{l}02-06-20 \\
15\end{array}$ & 453 & 78 & 13.70 & 934 & 2.90 & 9.80 & 1.51 & 0.23 \\
\hline $\begin{array}{l}19-09-20 \\
14\end{array}$ & & & 7.80 & 496 & 3.12 & 11.20 & 1.09 & 0.45 \\
\hline $\begin{array}{l}04-08-20 \\
14\end{array}$ & 243 & 92 & 6.40 & 372 & 2.93 & 10.50 & 0.83 & 0.34 \\
\hline $\begin{array}{l}25-04-20 \\
14\end{array}$ & & 96 & 7.30 & 460 & 3.22 & 12.00 & 1.83 & 0.37 \\
\hline $\begin{array}{l}04-04-20 \\
14\end{array}$ & 256 & 87 & 5.90 & 428 & 3.20 & 12.20 & 1.00 & 0.35 \\
\hline $\begin{array}{l}10-03-20 \\
14\end{array}$ & 233 & 88 & 4.70 & 347 & 2.99 & 12.00 & 1.27 & 0.22 \\
\hline $\begin{array}{l}22-07-20 \\
13\end{array}$ & & 90 & 7.40 & 352 & 3.25 & 12.40 & 1.55 & 0.37 \\
\hline $\begin{array}{l}25-03-20 \\
13\end{array}$ & & & 13.10 & 783 & 3.76 & 12.10 & 2.23 & 0.45 \\
\hline $\begin{array}{l}01-11-20 \\
12\end{array}$ & & & 9.70 & 563 & 3.38 & 11.70 & 1.55 & 0.40 \\
\hline
\end{tabular}

The uniqueness of the case is attributed to the JAK2 $2^{\mathrm{V} 617 \mathrm{~F}}$ mutation and a high number of $\mathrm{mMK}$ observed in the peripheral blood of the patient. The pathogenesis of vascular thrombosis associated with JAK2 $2^{\mathrm{V} 617 \mathrm{~F}}$ mutations is still not well understood. However, the cause appears to be associated with increased heparanase activity under the JAK2 mutation, which would directly increase Tissue Factor concentration (TF) and decrease Tissue Factor Pathway Inhibitor (TFPI) activity leading to increased factor $\mathrm{Xa}$ and subsequent activation of the coagulation cascade. This situation implies an increased thrombosis $[14,15]$.

In addition to this evidence, there are studies in animal models with the JAK2 mutation, showing that megakaryocytes become hypersensitive to fibrinogen, thrombopoietin and 
other endogenous stimulant compounds. Thus, this alteration in the physiology of megakaryocytes could be related to thrombocytosis and to thrombotic events due to a higher reactivity also of platelets to thrombin $[16,17]$.

The patient on this case had mMK-compatible cells in the bone marrow while demonstrating an increase in the number of these cells in the circulation. In this way, what would be the influence of the large amount of mMK? Can mMK be associated with a greater predisposition to thrombotic events? Since they could respond in the same or similar way to normal megakaryocytes in the condition of the JAK2 mutation (Figure 3), we need to analyze what is the impact on patient survival?

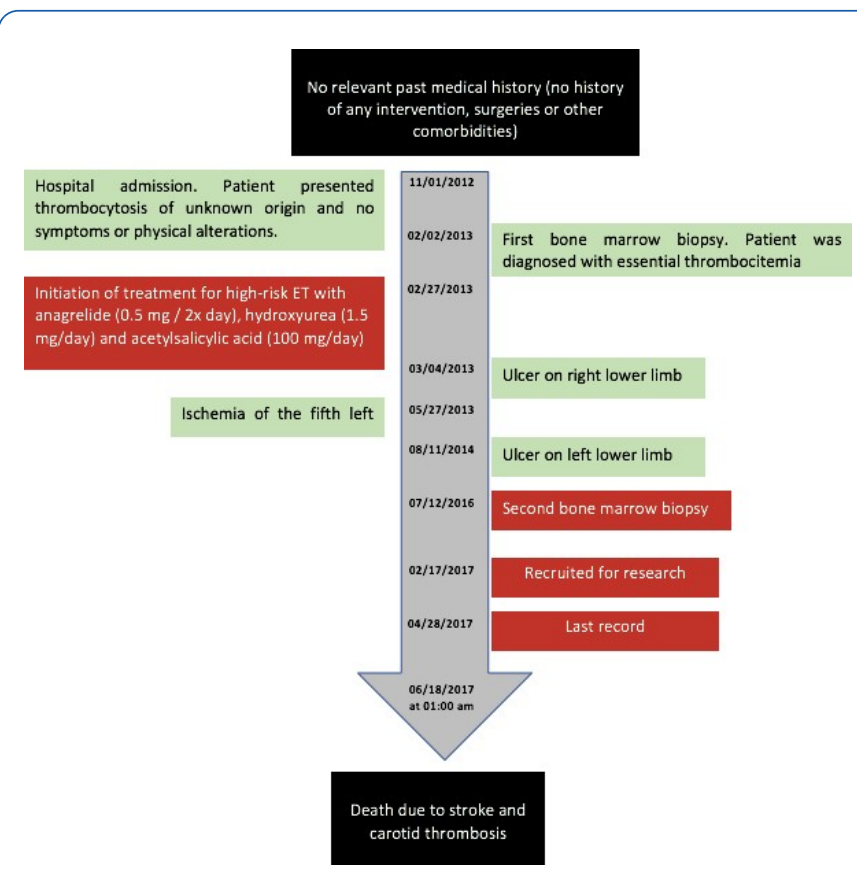

Figure 3 Patient diagram. Diagram according to the care case report guidelines showing trajectory and interventions performed on the patient in chronological order.

\section{Conclusion}

The presentation and outcome of the case did not correspond to many of the proposed paradigms for essential thrombocythemia and raised questions about the role of $\mathrm{mMK}$ in the pathogenesis of the disease. Therefore, there is a need for more related studies in order to prove the importance of the quantification of $\mathrm{mMK}$ in peripheral blood of patients with ET. Perhaps in the future, we will use quantification of $\mathrm{mMK}$ in the clinic, with new perspectives for the prognosis of these patients.

\section{Author's Contributions}

MAP wrote the case report and was the principal investigator; SN was responsible for the acquisition of data and drafting the manuscript; BP recruited the patient and elaborated the consent form; HK evaluated critically and designed the manuscript. All authors read and approved the manuscript.

\section{Funding}

Not applicable.

\section{Consent for Publication}

Written informed consent was obtained from the patient for publication of this case report and any accompanying images. A copy of the written consent is available for review by the Editor-in-Chief of this journal.

\section{Competing Interests}

The authors declare that they have no competing interests.

\section{Compliance with Ethical Standards}

The manuscript has been read and approved by all qualified authors.

\section{References}

1. Lussana F, Caberlon S, Pagani C, Kamphuisen PW, Büller HR, et al. (2009) Association of V617F Jak2 mutation with the risk of thrombosis among patients with essential thrombocythaemia or idiopathic myelofibrosis: A systematic review. Thromb Res124: 409-417.

2. Bayrak S, Bektas H, Duzkoylu Y, Guneyi A, Cakar E (2014) Acute abdomen resulting from concurrent thrombosis of celiac trunk and superior mesenteric artery. Case Reports Gastrointestinal Medicine 2014: 1-3.

3. Chen W, Wang XL (2018) Cerebral venous sinus thrombosis as the first manifestation of JAK2V617F-positive essential thrombocythemia. Chin Med J (Engl) 131: 748-750.

4. Averback P, Moinuddin M (1977) Pericarditis as a manifestation of essential thrombocythemia. Can Med Assoc J 117: 154-156.

5. Goasguen JE, Bennett JM, Bain BJ, Brunning RD, Vallespí MT, et al. (2016) Quality control initiative on the evaluation of the dysmegakaryopoiesis in myeloid neoplasms: Difficulties in the assessment of dysplasia. Leuk Res 45: 75-81.

6. Pich A, Riera L, BeggiatoE, Nicolino B, Godio L, et al. (2012) JAK2V617F mutation and allele burden are associated with distinct clinical and morphological subtypes in patients with essential thrombocythaemia. J Clin Pathol 65: 953-955.

7. Arber DA, Orazi A, Hasserjian R, Thiele J, Borowitz MJ, et al. (2016) The 2016 revision to the World Health Organization classification of myeloid neoplasms and acute leukemia. Blood 127: 2391-2405

8. Peluso B (2017) Padronização e avaliação da expressão de células cd34+/cd61+ ou cd34+/cd 41+ e cd61+/cd41+ circulantes em portadores de trombocitemia essencial.. Dissertação (Mestrado em Patologia Geral) - Faculdade de Medicina, Universidade Federal Fluminense, Niterói. 
9. Ziakas PD (2008) Effect of JAK2 V617F on thrombotic risk in patients with essential thrombocythemia: measuring the uncertain. Haematologica 93: 1412-1414.

10. Casini A, Fontana P, Lecompte TP (2013) Thrombotic complications of myeloproliferative neoplasms: risk assessment and risk-guided management. J Thromb Haemost 11: 1215-1227.

11. Carobbio A, Thiele J, Passamonti F, Rumi E, Ruggeri $M$, et al. (2011) Risk factors for arterial and venous thrombosis in WHOdefined essential thrombocythemia: an international study of 891 patients. Blood 117: 5857-5859.

12. Landolfi R, Di Gennaro L, Barbui T, De Stefano V, Finazzi G, et al. (2007) Leukocytosis as a major thrombotic risk factor in patients with polycythemia vera. Blood 109: 2446-2452.

13. Tefferi A, Barbui T (2019) Polycythemia vera and essential thrombocythemia: 2019 update on diagnosis, risk-stratification, and management. Am J Hematol 94: 133- 143.
14. Stankowska K, Gadomska G, Boinska J, Michalska M, Bartoszewska-Kubiak A, et al. (2016) Extrinsic blood coagulation pathway and risk factors for thrombotic events in patients with essential thrombocythemia. Pol Arch Med Wewn 126: 340-346.

15. Kogan I, Chap D, Hoffman R, Axelman E, Brenner B, et al. (2016) JAK-2 V617F mutation increases heparanase procoagulant activity. Thromb Haemost 115: 73-80.

16. Hobbs $C M$, Manning $H$, Bennett $C$, Vasquez $L$, Severin $S$, et al. (2013) JAK2V617F leads to intrinsic changes in platelet formation and reactivity in a knock-in mouse model of essential thrombocythemia. Blood 122: 3787-3797.

17. Maldonado-Peña J, Rivera K, Ortega $C$, Betancourt M, Lugo JE, et al. (2016) Can monocytosis act as an independent variable for predicting deep vein thrombosis?. International Journal of Cardiology 219: 282-284. 